\title{
Pruning Strategies to Maximize Tropical Mango Production From the Time of Planting to Restoration of Old Orchards
}

\author{
Thomas L. Davenport ${ }^{1}$ \\ University of Florida, Institute of Food and Agricultural Sciences, Tropical Research and Education Center, 18905 \\ SW 280 Street, Homestead, FL 33031
}

\begin{abstract}
Additional index words. juvenility, flowering management program, rejuvenation, size control
Summary. Pruning is an unavoidable necessity of virtually all arboreal fruit crops. In the tropics and subtropics, pruning of mango (Mangifera indica $\mathrm{L}$.) is particularly important due to its tendency for frequent flushes, especially in humid tropics. Commercial orchards must maintain control of both tree size and orchard productivity in order to remain productive. Tip, formation, and severe pruning can be used in a variety of circumstances to produce predictable and useful results for a variety of purposes. For example, tip pruning can be used to encourage frequent flushing and branching of young trees to bring them into commercial production years earlier than if left alone. It can also stimulate timely flushes of lateral stems in an annual program to maintain tree size and prepare trees for synchronous flowering. Formation pruning shapes trees in an overgrown orchard to receive the maximum amount of light for high productivity and sets them up for annual pruning in a flowering management program. Severe pruning coupled with subsequent tip pruning of huge, nonproductive trees facilitates rapid restoration of orchard production. Each of these types of pruning can be used to get mango trees into production quickly and thereafter maintain maximum annual production while maintaining their desired size.
\end{abstract}

Pruning is an operation familiar to all arborists and horticulturists managing growth and reproductive habits of fruit trees. It is used when trees require training to specific shapes, such as adapting to trellises, or to stimulate development of lateral branching that forms reproductive spurs in temperate climate trees (Summerville, 1996). Such manipulations are generally selective and labor intensive. Pruning trees grown on a large scale in the tropics, however, require different strategies to keep them highly productive for many years. One example is the mango, which has been the subject of numerous pruning strategies in various parts of the world (Gross, 1996; Medina-Urrutia and Núñez-Elisea, 1996; Oosthuyse, 1992; Oosthuyse, 1994; Oosthuyse, 1997; Oosthuyse and Jacobs, 1996; Poffley, 1994; Rao, 1971; Stassen et al., 1999).

Mango trees are grown in warm conditions of the tropics and subtopics that promote frequent flushes of vegetative growth. In the tropics, the age of the last flush is the dominant factor regulating flowering of mango (Davenport, 2003). Stems must be in rest for sufficient time, generally about 4 to 5 months, to be induced to flower in the absence of chilling temperatures. Moderately cool temperatures that can reach deep into tropical dry and high elevation locations during winter months provide additional stimulus to flower on stems of a given age.

Mango trees generally begin commercial production in three to four years after planting and continue to produce increasing yields as canopies enlarge until shading by adjacent trees forces the growth upwards and out of reach of harvesters. Lower branches supporting previous year's productive stems die back due to shading by higher branches. Flowering and fruit production in mango occurs on stem terminals; therefore, as canopy size increases, production

${ }^{1}$ To whom reprint requests should be addressed; e-mail tldav@ifas.ufl.edu. moves to the top as competition for available light continues. Eventually, fruit production occurs so high in that canopy that it becomes unreachable. This generally occurs by about 20 years after planting. At that point, orchards may be abandoned or pushed out and replanted with young trees that are more manageable.

Three pruning strategies have been developed to 1) prevent trees from getting large through annual pruning as part of a flowering management program;2) reshape intermediate sized tress to smaller, more manageable sizes; or 3) completely rejuvenate large trees that are no longer productive due to their size and height. This article describes techniques recommended to address each of these issues and why each technique will maximize yields far beyond the normal life span of a mango orchard by keeping vegetative growth in check.

To understand how each of the pruning techniques works, one must first understand the growth habit of mango trees and the interaction of water and nitrogen on growth from first planting to the point when they become too large for commercial use. All growth occurs in periodic ephemeral flushes of vegetative or reproductive shoots initiating in apical or lateral buds on terminal resting stems. The term stems refers to vegetative shoots that have become quiescent to become the first intercalary unit at the terminal (Fig. 1) (Davenport and Núñez-Elisea, 1997). A shoot usually produces about 12 nodes that bear leaves if it is vegetative, lateral inflorescences if it is reproductive, or both leaves and inflorescences within the same nodes if it is mixed. A flush can be described as initiation of shoot growth from a group of stems borne on linked branches.

Although mango is considered drought tolerant (Schaffer et al., 1994), adequate water is essential for growth. Water deficits discourage initiation of flushes, which may provide the required period of rest to encourage flowering after alleviation of water stress (Núñez-Elisea and Davenport, 1994). When soil water content is adequate, leaf nitrogen affects the frequency of flushes. Experience has shown that leaf nitrogen levels higher than $1.4 \%$ encourage frequent vegetative flushes that prevent flowering during warm temperature conditions due to insufficient accumulation of time in rest between flushes

Fig. 1. Diagram of a typical mango terminal stem showing three intercalary units, each separated by a tight cluster of closely spaced nodes, or intercalations, representing the termination of each previous flush of vegetative growth as described by (Davenport and Núñez-Elisea, 1997). Tip pruning stimulates initiation of lateral shoots represented by the diagonal lines radiating from the stems. If the cut is made immediately distal to an intercalation (grey circles), then six to ten lateral shoots initiate from the cluster of quiescent buds in the intercalation, forming branching stems (gray diagonal lines) in a radiating pattern. If a prune cut is made at or near the distal terminus of an intercalary unit (black circles), shoots are initiated from quiescent lateral buds in the most proximal nodes to the cut (black diagonal lines), usually resulting in two to four lateral stems.
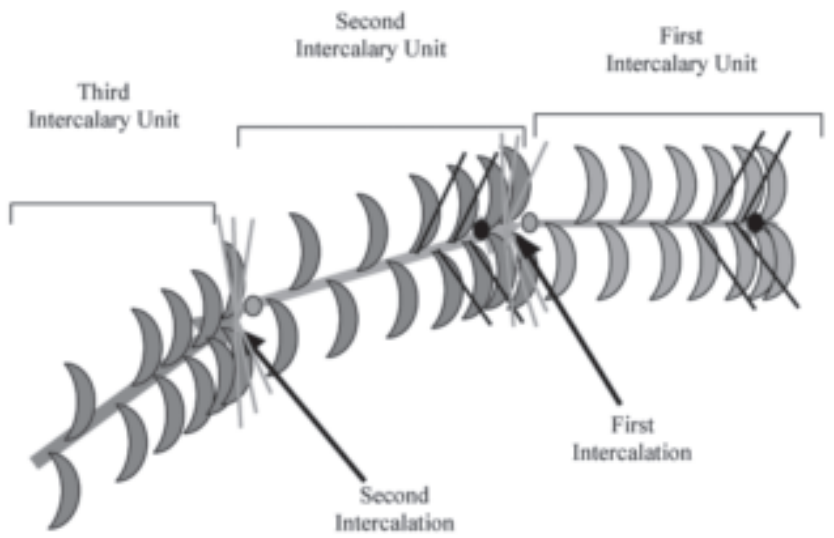

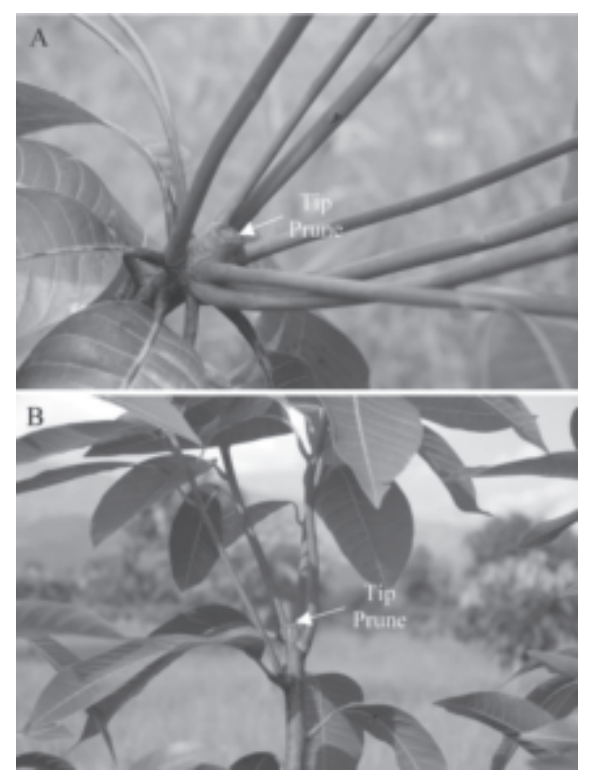

Fig. 2. (A) Ten lateral stems resulting from a tip prune immediately distal to an intercalation. (B) Four lateral stems resulting from a tip prune near the distal terminus of an intercalary unit. Photos depict stems from trees in the Dominican Republic.

(Davenport, 2003). Nitrogen levels below $1.0 \%$ tend to discourage initiation of growth flushes. Soil water content and leaf nitrogen levels, therefore, must be considered in order to understand the response of tropical mango trees to pruning.

\section{TIP PRUNE}

Tip pruning is defined as pruning terminal stems anywhere from the apex to a point down the stem that is no larger than $1 \mathrm{~cm}$ in diameter. This span includes green barked wood on two or three intercalary units (Fig. 1). Extension growth flushes of mango trees are evident in branches from the terminal stems down through scaffold limbs to the graft union. Each flush of vegetative growth is characterized by long internodes that gradually become close together forming a cluster of buds at the termination of each flush. The growth record of these flushes in branches has been described as intercalary units and the cluster of leaves and buds at the terminus of each intercalary unit as intercalations numbered from the stem terminus (Davenport and Núñez-Elisea, 1997).

Given adequate water and nutrition, tip pruning forces rapid initiation of dormant lateral stem buds to form lateral shoots in a pattern determined by the location of the pruning cut (Fig. 1). Prune cuts made immediately distal to any intercalation usually result in initiation of six to ten lateral vegetative shoots clustered in the intercalation (Figs. 1 and 2A). In contrast, prune cuts made near the stem tip or below intercalations usually result in two to four lateral stems originating from the axillary buds at the bases of leaves nearest the cut (Figs. 1 and 2B).

Pruning the tips of mango stems is done for several purposes: 1) to stimulate branching flushes of lateral shoots through repeated prun- ings in young trees to form a dense spreading canopy that flowers a year or two earlier than normal for early commercial production of fruit;2) to stimulate branching in a synchronous vegetative flush of growth throughout the tree canopy and to remove growth inhibiting panicle structures left from the previous season's flowering and crop in preparation for an annual flowering program; and 3) to restore quickly the productivity of shape-pruned or severely pruned trees by stimulating flushes of multiple branching stems through repeated prunings, which result in increased production.

\section{SHORTENING THE JUVENILITY PERIOD OF SMALL TREES}

Most mango trees arrive from the nursery with only one central stem. After planting, normal development is characterized by frequent flushes of vegetative growth with little branching, especially in the popular cultivar, 'Keitt' (Fig. 3A and B). Juvenile trees do not flower due to the short intervals of 2 to 3 months between vegetative flushes (Davenport and NúñezElisea, 1997; Núñez-Elisea and Davenport, 1995). It normally takes three to four years to achieve sufficient numbers of stems and height to reduce this frequency of growth flushes. It is only then that sufficient stem maturity can be achieved to allow flowering to occur and produce a commercially viable crop.

Frequent tip pruning of young trees forces frequent initiation of lateral shoots, forming four to seven shoots per stem with each cut. If this pruning is repeated every 3 months using pruning shears or a machete on the subsequent lateral branches, trees begin to form a full canopy as a result of the exponential increase in branching (Fig. 3C and D). For example, the 'Keitt' trees in Fig. 3B and D are both one year old. The tree in Fig. 3B was not pruned whereas the tree in Fig. 3D was pruned three times during the first year of growth. The flush frequency was already reduced as evidenced by the reduced height of the tip-pruned tree. The fourth prune, done after the photo was taken, was accomplished in August to stimulate a synchronized September vegetative flush in preparation for synchronized flowering at the anticipated normal flowering time in January and February. Experience has shown that if a second vegetative flush does not occur in November or December after the September flush in response to the tip prune, this tree will flower and produce a crop.

Fig. 3. (A) Diagram of branch architecture of a typical mango tree that has never been tip pruned. (B) Matching photo of a typical 1-year-old 'Keitt' tree in the Dominican Republic that has never been pruned. (C) Diagram demonstrating increased branching response (four branches per prune event) after 1 year following three tip-pruning events (circles) at 3-month intervals. (D) Photo of a typical one-year-old 'Keitt' tree in the Dominican Republic after three previous tip-prune events at levels 1,2, and 3 in 3-month intervals. Photo was taken immediately before the fourth tip prune at level 4 to further increase stem number in September for anticipated flowering response in January-February.
The height of the first pruning point, which ultimately determines the height of the lowest branches, is determined by grower preference; however, it should not be lower than the second intercalation above the graft union. Trees will usually be ready to begin commercial production after the fourth pruning due to the reduction in flushing frequency that would otherwise continue unchecked in nonpruned trees. The final prune in the northern hemisphere tropics should be done in August or early September for the resulting stems to achieve sufficient maturity by the time of natural flowering in January and February. A similar strategy has been suggested for dooryard mango trees grown in the subtropics (Campbell and Campbell, 2005)

\section{TIP PRUNING TO STIMULATE A SYNCHRONIZING FLUSH OF VEGETATIVE GROWTH}

Tip pruning mature trees quickly results in one flush of lateral shoot growth if water is adequate and leaf nitrogen levels are in a range of $1.1 \%$ to $1.4 \%$ (Davenport, 2003). This response is critical to the success of a flowering management program. If the lateral stems produced by this prune event remain in rest for 4 to 5 months, then flowering will usually occur when initiated to grow either by cool temperatures or by foliar application of ethephon or a nitrate salt, such as potassium, calcium, or ammonium nitrate in warm tem-
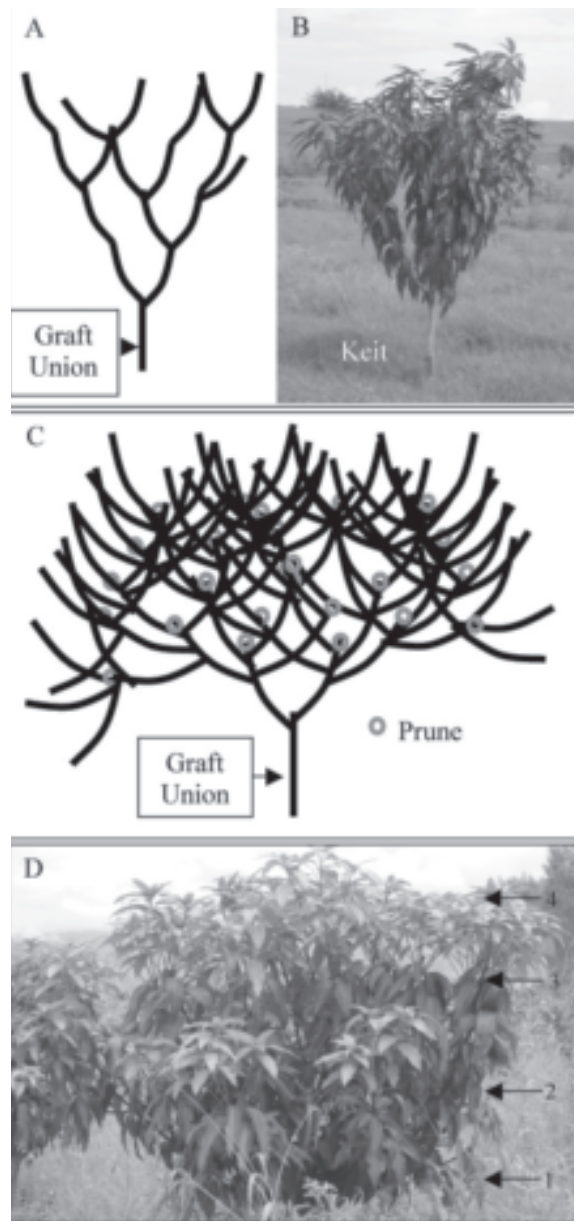


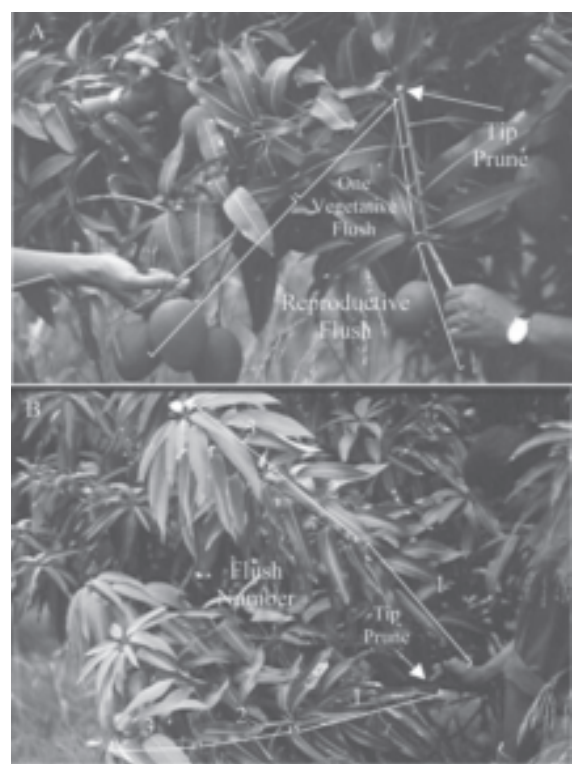

peratures $\left(>20{ }^{\circ} \mathrm{C}\right.$, night) (Davenport, 2000, 2003; Davenport and Núñez-Elisea, 1990, 1997; Núñez-Elisea and Caldeira, 1988). Leaf nitrogen levels $>1.4 \%$ encourage a second flush of vegetative growth soon after that following the prune if adequate water is available. This second vegetative growth flush eliminates the possibility of timely flowering in cool temperatures or when sprayed with nitrate as described above. Figure 4A demonstrates floral initiation that was stimulated by a foliar spray of $4 \%$ potassium nitrate 5 months after tip pruning in warm, tropical conditions. Only one vegetative growth flush occurred after tip pruning. In contrast, Fig. 4B displays a tree with a leaf nitrogen content of $1.6 \%$ that produced
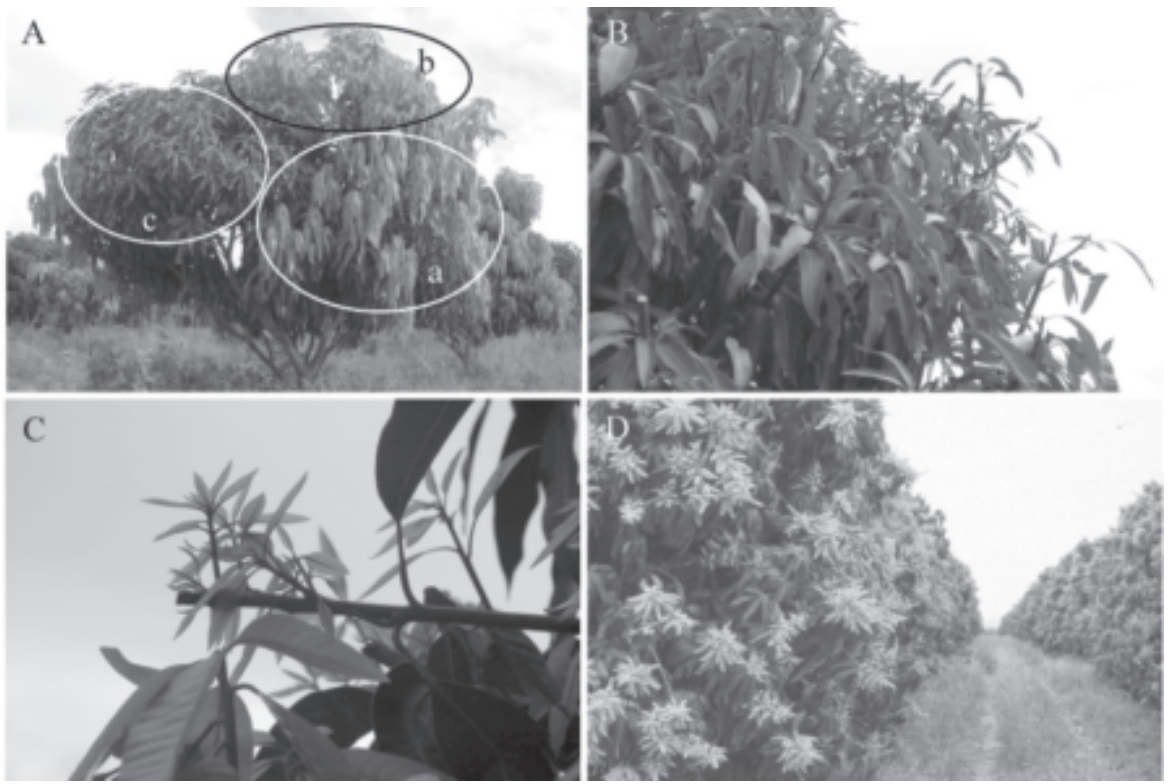

Fig. 5. (A) Asynchronous vegetative growth within a 'Haden' tree canopy before the normal flowering season promotes asynchronous and irregular flowering. Recent shoots in the limp, red-leaf stage of development are in section (a), stems of about 2 months of age are in section (b), and stems older that 3 months are in section (c). (B) Tip pruning the orchard promotes a synchronized flush of vegetative growth throughout canopies of individual trees and the entire orchard. (C) Tip pruning stimulates synchronous initiation of numerous lateral shoots per cut stem resulting in potentially more panicle bearing stems than available before pruning. (D) Synchronous flowering occurs even in warm temperatures if the resulting stems are stimulated to grow after reaching sufficient stem maturity (about 4 months). Photos depict 'Haden' trees in Venezuela, (A and B), Dominican Republic, $(\mathbf{C})$, and Honduras (D).
Tip pruning is, thus, done to assist in uniform flowering response in a flowering management program, impart a desired shape to the canopy, and improve the productivity of bearing trees by significantly increasing the number of bearing stems.

Tip pruning is best done with sharp machetes and ladders or other means where labor is available to reach the tops of trees in the tropics (Fig. 6A). Avariety of pruning machines (Fig. 6B) are also available for rapid pruning of large orchards, but they are expensive unless several growers share the cost. One should prune most of the terminal stems in the canopy for best results (Fig. 5B). The cuts should be no deeper than the third intercalary unit to discourage unwanted second flushes. In the Caribbean islands and Central America, tip pruning in early September allows sufficient age for optimum flowering of the resulting flush in January and February.

\section{SHAPE OR FORMATION PRUNE}

The purpose of shape pruning is to reduce the dimensions of the canopy in trees that are becoming overcrowded or to make it more convenient for tip pruning as part of the flowering management program. This type of prune requires cutting branches ranging in size from 2 to $10 \mathrm{~cm}$ in diameter depending upon the original size of the trees. The depth of prune into the canopy must be at least one meter inside the final desired dimensions in order to allow for regrowth of the canopy (Fig. 7A). Figure 7B displays shape pruned trees in the same row as those shown in Fig. 7A. Background trees provide comparison of original size. The resulting regrowth was tip pruned two times during the year following the shape prune event and to be pruned a third time soon after the photo was taken (Fig. 7C). Tree response was a quick restoration of the original number of stems at a lower canopy level than before and suppression of frequent

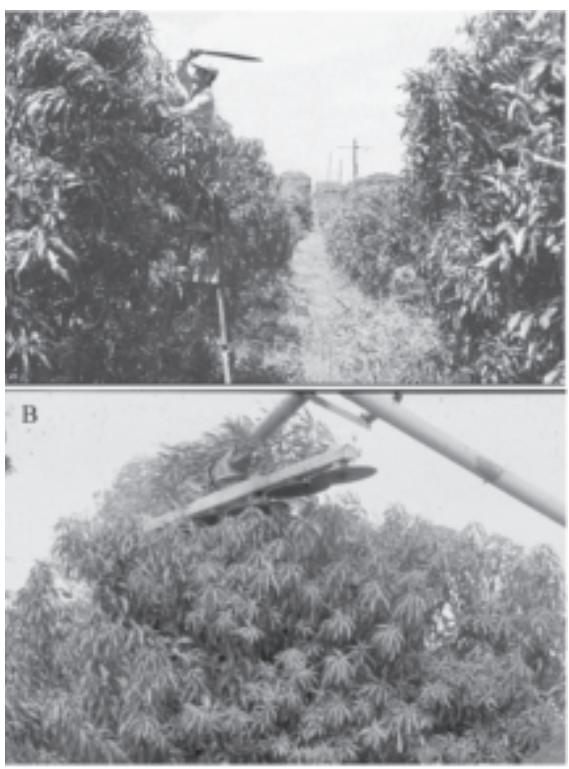

Fig. 6. 'Haden' orchard being tip pruned by machete in Honduras (A) and by a mechanical pruning machine attached to a tractor (B). 

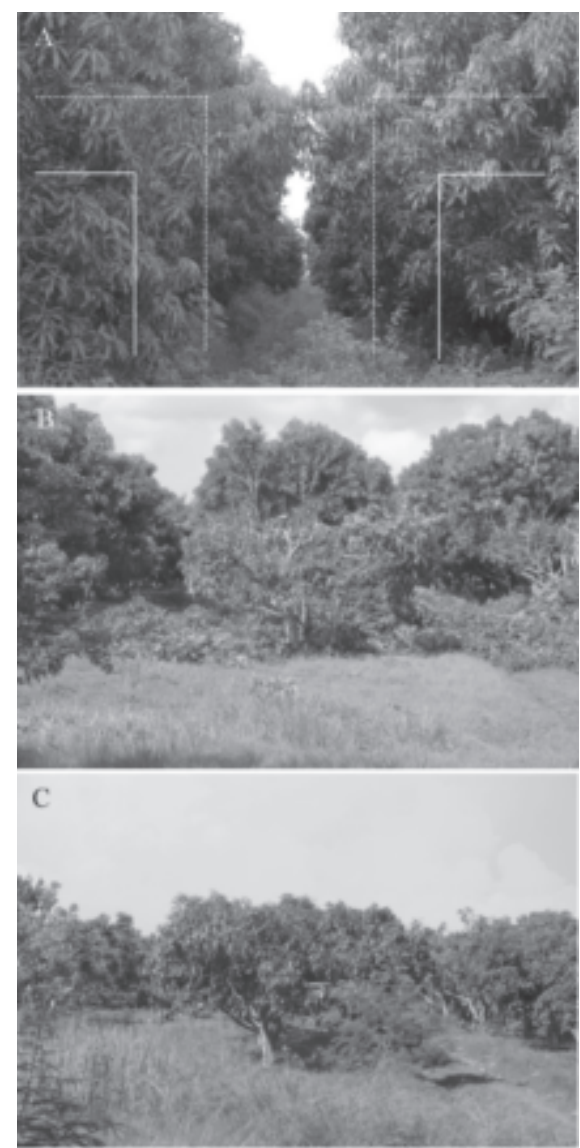

Fig. 7. (A) Shape pruning trees should be performed about $1 \mathrm{~m}$ below and inside (solid lines) the final desired dimension after regrowth (dashed lines). Typical dimensions after regrowth are $4 \mathrm{~m}$ high and sufficiently wide to provide light to the base or skirts of the canopy within rows. (B) Recently shape pruned 'Haden' tree in the same Dominican Republic orchard as depicted in (A). Remaining nonpruned trees in row are in the background. (C) Regrowth of the same tree 1 year later after two tip prunings to increase stem branching, check extension growth, and retard subsequent flushing to allow flowering in sufficiently mature stems during the flowering season. Note that trees in the background were pruned soon after the photo in $\mathbf{B}$ was taken in the previous year. Orchard trees are now amenable to tip pruning as part of the annual flowering management program (Davenport, 2003).

flushing, thus making the tree more likely to flower in the next flowering season. Without tip pruning following a shape prune event, the resulting growth flushes from such cuts are always frequent and vigorous with little branching. They commonly reach $>2 \mathrm{~m}$ in as many as 11 flushes in one year as indicated in Fig. 8 displaying a branch resulting from shape pruning that occurred 12 months previous. This vigorous growth prevents trees from flowering in the tropics until they reach their original prepruned dimensions and return to stable, infrequent flushes. Such vigorous growth is similar to that of young trees and, thus, must be treated in the same manner as young trees with frequent tip pruning after the original shape prune to maximize branching. If tip pruned three or four subsequent times during the year, trees usually return to normal flush

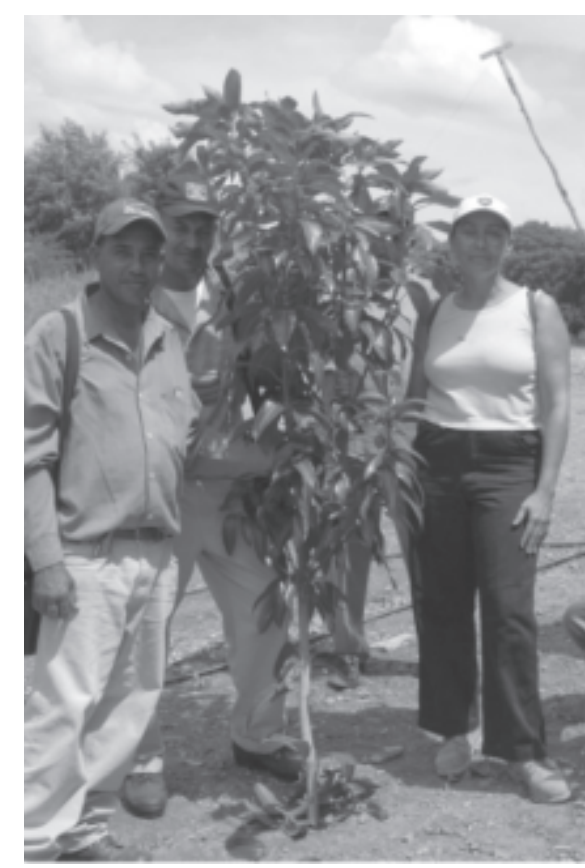

Fig. 8. One year of accumulated nonpruned growth from a shape pruned 'Haden' mango branch in the Dominican Republic. Eleven intercalary units were present on this branch indicating 11 flushes of vegetative growth (a bit less than one flush per month) occurred subsequent to shape pruning in the previous year.

frequencies by suppressing subsequent flushes more with each tip prune such that they will be capable of flowering 5 months following the last tip prune.

\section{SEVERE PRUNE}

Once mango trees become so large, and the canopy migrates upwards far beyond the reach of harvesters, it is no longer productive to maintain them (Fig 9A). Severe pruning is done to rejuvenate these large trees so they will re-grow to a size amenable to a flower management program. Regrowth of pruned trees is always located at the level where the prune cut was made; hence, if the cuts are made at 7 $\mathrm{m}$ high, that is where the new canopy begins. In this situation, growers soon find that the trees regain their height before going back into production. In contrast, severely pruning a tree at $1.5 \mathrm{~m}$ (Figs. 9B and 10A) causes reestablishment of the canopy low and within easy reach of pruners and fruit pickers (Fig. 10B). Frequent tip pruning of the resulting shoots reduces the flush frequency back to normal usually by one year resulting in resumption of flowering with production at no higher than three meters. These trees can then be maintained at a desired canopy height and dimension for many years using annual tip pruning as part of the annual flowering management program.

\section{GENERAL CONSIDERATIONS}

Canopy height and width of mango trees depends upon tree spacing. Spacing between trees within rows should not influence the desired canopy height unless one desires individual trees within rows as opposed to hedgerows. Continuous shading of leaves always results in loss of productive branches in the lower portions of the canopy. Trees must be adjusted in height so that shading does not occur in skirts (lowest portion) of the tree canopy. Row spacing of $8 \mathrm{~m}$ requires trees no higher than $4 \mathrm{~m}$ and sides no more than $3 \mathrm{~m}$ from the trunk to allow passage of equipment and penetration of light to the lower canopy.

The advantages of annual tip pruning is that it provides reliable synchronized flowering in selected rows year after year in trees that remain the same size for many years. Although tip pruning is labor intensive, mechanical pruners are available that make the job easier and rapid so that many orchards can be pruned in a short period of time. Shape pruning and the subsequent tip prunings are more labor intensive than annual tip pruning but only need to be done once to bring the trees into production while controlling the size of the new canopy. The economics of pruning need to be evaluated in detail, but growers who are using these strategies are realizing good economic returns due to increased and dependable yields (Maximo Jerez, Mango Cluster, Dominican Republic, personal communication). Small acreage growers can afford hand pruning using machetes and small power tools along with ladders or mobile equipment to reach the tops of the canopy. For larger operations, mechanical pruners attached to a tractor are more cost effective than hand tools (Jose Vera, Venezuelan grower, personal communication). Regardless of the cost, annual tip pruning is more cost effective than letting an orchard outgrow its productivity.

\section{Literature Cited}

Campbell, R.J. and C.W. Campbell. 2005. Size does matter: pruning for perfection. Fairchild Tropical Garden, Miami, Fla. 10 Oct. 2005. http://www. ftg.org/horticulture/mangopruning.html.

Davenport, T.L. 2000. Processes influencing floral initiation and bloom: the role of phytohormones in a conceptual flowering model. HortTechnology 10:733-739.

Davenport, T.L. 2003. Management of flowering in three tropical and subtropical fruit tree species. HortScience 38:1331-1335.

Davenport, T.L. and R. Núñez-Elisea. 1990. Ethylene and other endogenous factors possibly involved in mango flowering. Acta Hort. 275:441-448.

Davenport, T.L. and R. Núñez-Elisea. 1997. Reproductive physiology, p. 69-146. In: R.E. Litz (ed.). The mango: Botany, production and uses. CAB Intl., Wallingford, U.K

Gross, E.R. 1996. Pruning mango to increase yield. Acta Hort. 455:538-542.

Medina-Urrutia, V.M. and R. Núñez-Elisea. 1996. Mechanical pruning to control tree size, flowering and yield of mature 'Tommy Atkins' mango trees. Acta Hort. 455:305-314.

Núñez-Elisea, R. and M.L. Caldeira. 1988. Adelanto de la floración y cosecha en mango 'Haden' con aspersiones de nitrato de amonio. Anais IX Congresso Brasileiro de Fruticultura, Campinas, Sao Paulo, Brasil. p. 561-566.

Núñez-Elisea, R. and T.L. Davenport. 1994. Flowering of mango trees in containers as influenced by seasonal temperature and water stress. Scientia Hort. 58:57-66.

Núñez-Elisea, R. and T.L. Davenport. 1995. Ef- 

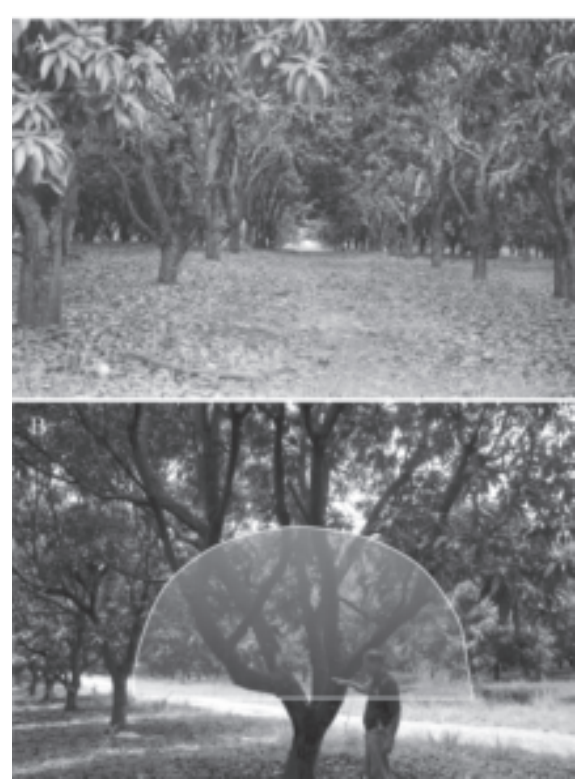

Fig. 9. (A) Overgrown 'Haden' mango trees in Venezuela. All fruit production occurs in the top of the canopy beyond reach of individuals harvesting the fruit. (B) If such trees are severely pruned at the level indicated by the hand of the plantation manager and the regrowth is tip pruned each three months through the following year with the last tip prune event occurring in September, the resulting canopy will fill the translucent area and usually go back into production the following January and February after losing only one season of flowering.
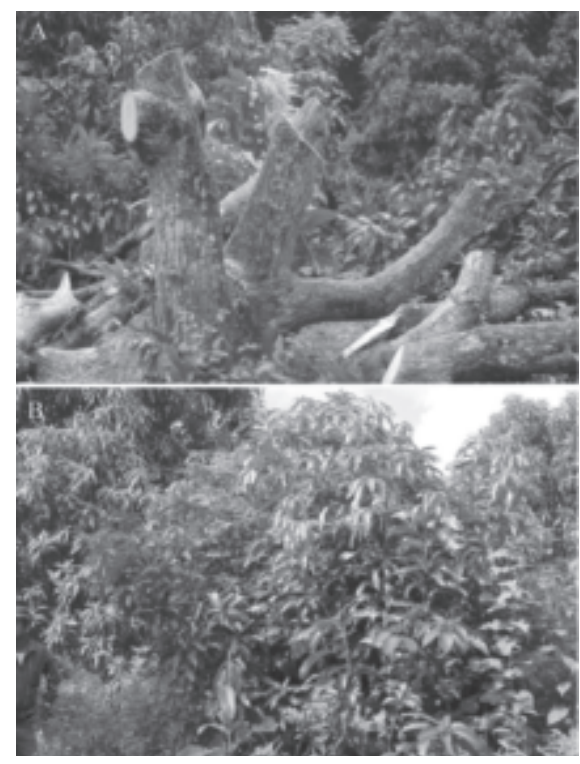

Fig. 10. Severe pruning of large trees (A) should be made with near vertical cuts to insure good rainwater drainage to discourage decay of exposed wood on the cut surface. Previously shaded tree trunks now exposed to direct sun should be white washed to prevent sunburn of the bark. (B) Severe pruning rejuvenates large trees such as these in the Dominican Republic and Venezuela by bringing the canopy down to a functional shape and size that is amenable to production management. fect of leaf age, duration of cool temperature treatment, and photoperiod on bud dormancy release and floral initiation in mango. Scientia Hort. 62:63-73.

Oosthuyse, S.A. 1992. Ideas on pruning of mango trees. S. Afr. Mango Growers Assn. Yrbk. $12: 1-7$.

Oosthuyse, S.A. 1994. Pruning of Sensation mango trees to maintain their size and effect uniform and later flowering. S. Afr. Grower's Assn. Yrbk. 14:1-6.

Oosthuyse, S.A. 1997. Some principles pertaining to mango pruning, and the adopted practices of pruning mango trees in South Africa. Acta Hort. 455:413-421.

Oosthuyse, S.A. and G. Jacobs. 1996. Flowering synchronization of 'Sensation' mango by winter pruning. Acta Hort. 455:422-430.

Poffley, M. 1994. Mango pruning in the top end. Primary Ind. Fisheries N. Territory Austral. Agnote No. 598. 4 p.

Rao, V.N.M. 1971. A note on pruning as a remedy for irregular bearing in mango. Andhra Agr. J. 18:242-245.

Schaffer, B., A.W. Whiley, and J.H. Crane. 1994. Mango, p. 165-197. In: B. Schaffer and P.C. Anderson (eds.). Handbook of environmental physiology of fruit crops. Vol. 2. Chapter 8 Sub-tropical and tropical crops. CRC Press, Boca Raton, Fla.

Stassen, P.J.C., H.G. Grove, and S.J. Davie. 1999. Tree shaping strategies for higher density mango orchards. J. Appl. Hort. 1:1-4.

Summerville, W. 1996. Pruning and training fruit trees. Inkata Press, Victoria, Australia. 